\title{
Pharmaceutical analysis of different antibiotic regimens in the treatment of lower respiratory tract infection
}

\author{
LIN ZHANG $^{1}$, BENHONG LIU ${ }^{2}$ and CHUNBIN WANG ${ }^{3}$ \\ ${ }^{1}$ Management of Hygienic Materials; Departments of ${ }^{2}$ Respiratory Medicine and ${ }^{3}$ Pharmacy, \\ Dongying People's Hospital, Dongying, Shandong 257091, P.R. China
}

Received March 23, 2018; Accepted June 29, 2018

DOI: $10.3892 /$ etm.2018.6437

\begin{abstract}
The present study aimed to discuss and compare the effects and expenses of different antibiotic regimens in the treatment of lower respiratory tract infection (LRTI). A retrospective analysis was performed on 200 patients diagnosed with LRTI and treated at the Department of Respiratory Medicine of Dongying People's Hospital from February 2015 to May 2017. The patients were randomly divided into Group A, Group B, Group C and Group D, with 50 cases in each group, and were treated with ceftriaxone sodium, ceftizoxime sodium, levofloxacin and azithromycin, respectively. Venous blood of patients was collected. White blood cells (WBC) of venous blood were detected using a hematology analyzer and C-reactive protein (CRP) was tested with latex immunoturbidimetry. Moreover, therapeutic effects and drug costs of four different antibiotics were compared. No adverse reactions occurred to patients in the four groups during the treatment process. The value at each time point after treatment was significantly decreased compared with that at the previous time point before treatment within the group $(\mathrm{P}<0.01)$. The treatment expenses of patients in Group $\mathrm{A}$, Group B and Group D were significantly increased compared with those in Group $\mathrm{C}(\mathrm{P}<0.01)$, the treatment expenses of patients in Group B and Group D were significantly increased compared with those in Group A $(\mathrm{P}<0.01)$ and the treatment expenses of patients in Group D were significantly increased compared with those in Group B $(\mathrm{P}<0.01)$. Ceftriaxone sodium, ceftizoxime sodium, levofloxacin and azithromycin all have a good antimicrobial efficacy. The treatment condition of LRTI can be dynamically monitored by WBC and CRP which can accurately reflect the progression condition of patients' illness and the treatment effect. In economic terms, the treatment
\end{abstract}

Correspondence to: Dr Lin Zhang, Management of Hygienic Materials, Dongying People's Hospital, 317 Nanyi Road, Dongying, Shandong 257091, P.R. China

E-mail: aer6hm@163.com

Key words: ceftriaxone sodium, ceftizoxime sodium, levofloxacin, azithromycin, lower respiratory tract infection, treatment expense cost of levofloxacin is the lowest; thus, it is worthy of clinical popularization and application.

\section{Introduction}

Lower respiratory tract infection (LRTI) is mostly induced by infection or invasion of outside pathogenic microorganisms, such as bacteria, virus and chlamydia, into the human body. LRTI is the most common frequently occurring disease (1) and it is often complicated by pneumonia, bronchiectasis, bronchitis and other clinical symptoms, posing a severe threat to body health and quality of life of patients (2).

Research shows that white blood cell (WBC) count and $\mathrm{C}$-reactive protein (CRP) increase abnormally when there is an infection in the human body. Subsequently, WBC and CRP are two important reference indexes for diagnosing microbial infection and judging treatment effect, which are closely related to the severity degree of patients' illness $(3,4)$. With the continuous development of economy, the needs for health are increasing daily, while an increasing variety of antibiotics for treating LRTI and patients' wish for a speedy recovery lead to very severe clinical abuse of antibiotics. Injection of huge amounts of antibiotics into infected persons by medical workers results in a gradual enhanced drug resistance to LRTI pathogens, which not only influences the treatment effect on patients, but also gives rise to a continuous growth in the number of patients with nosocomial infection (5). Moreover, antibiotics are expensive, causing certain economic burden to patients and their families. LRTI is dominated by gram-negative bacterial infections, which are sensitive to broad-spectrum antibiotics, such as penicillins, ceftizoxime sodium, levofloxacin and azithromycin (6).

In the present study, four different antibiotic regimens including ceftriaxone sodium, ceftizoxime sodium, levofloxacin and azithromycin were applied to treat 200 LRTI patients, to determine the effects and costs of different antibiotic regimens in the treatment of LRTI.

\section{Materials and methods}

General data. A total of 200 patients with LRTI treated in the Department of Respiratory Medicine of Dongying People's Hospital (Dongying, China) from February 2015 to May 2017 were selected and retrospectively analyzed. The patients 
were randomly divided into group A $(n=50)$, group $B(n=50)$, group $\mathrm{C}(\mathrm{n}=50)$ and group $\mathrm{D}(\mathrm{n}=50)$. In group $\mathrm{A}$, there were 21 males and 29 females aged 16-59 years, with an average age of $(35.44 \pm 16)$ years and an average course of disease of $8.46 \pm 6.62$ days. In group B, there were 23 males and 27 females aged 18-65 years, with an average age of $35.14 \pm 2.01$ years and an average course of disease of $7.87 \pm 4.49$ days. In group C, there were 19 males and 31 females aged 20-63 years, with an average age of $34.52 \pm 2.35$ years and an average course of disease of $7.73 \pm 5.96$ days. In group D, there were 24 males and 26 females aged 19-66 years, with an average age of $34.68 \pm 2.46$ years and an average course of disease of $8.33 \pm 6.34$ days.

Inclusion and exclusion criteria. Inclusion criteria were: patients with definite symptoms of LRTI and diagnosed via chest X-ray examination, patients without receiving treatment within 1 month, patients without a history of antibiotic therapy, and patients who were informed, agreed to participate in the clinical study and signed the informed consent. Exclusion criteria were: patients with unconsciousness, confusion, complicated with severe heart, liver, kidney or hematopoietic dysfunction, mental diseases or a family history of mental illness or allergy to drugs, or pregnant or breastfeeding women. The present study was approved by the Ethics Committee of Dongying People's Hospital (Shandong, China) and signed written informed consents were obtained from the patients and/or guardians

Drug therapy. Patients in the 4 groups were treated with ceftriaxone sodium (cat. no. H10983036; Shanghai Roche Pharmaceutical Co., Ltd., Shanghai, China), ceftizoxime sodium (cat. no. H20060339; Suzhou Erye Pharmaceutical Co., Ltd., Suzhou, China), levofloxacin (cat. no. H20060508; Shandong Luoxin Pharmaceutical Group Ltd., Shandong, China), azithromycin (cat. no. H20010554; Xi'an Daheng Pharmaceutical Co., Ltd., Shaanxi, China) as follows: intravenous infusion of $2.0 \mathrm{~g}$ ceftriaxone sodium injection $+100 \mathrm{ml}$ $9 \%$ sodium chloride injection ( 2 times/day), intravenous infusion of $2.0 \mathrm{~g}$ ceftizoxime sodium $+100 \mathrm{ml} 9 \%$ sodium chloride injection ( 2 times/day), intravenous infusion of $0.3 \mathrm{~g}$ levofloxacin $+100 \mathrm{ml}$ 9\% sodium chloride injection (2 times/ day), and intravenous infusion of $1.0 \mathrm{~g}$ azithromycin $+100 \mathrm{ml}$ 9\% sodium chloride injection ( 2 times/day). All patients were treated for 1 week as 1 course of treatment.

Detection of WBC and CRP. Venous blood was drawn (4 ml) from patients at 1 day before treatment and at 1,4 and 7 days after treatment for WBC counting and CRP detection. WBC in the venous blood was detected using the DxH800 blood analyzer (Beckman Coulter, Inc., Shanghai, China), while $\mathrm{CRP}$ in the venous blood was detected via latex immunoturbidimetry using the AU5800 full-automatic biochemical analyzer (Beckman Coulter, Inc.), strictly according to instructions of the instrument and kit.

Observation indexes. After treatment for 7 days, the therapeutic effect of patients was evaluated and scored. Cured: lesions and clinical symptoms completely disappeared according to X-ray examination, there were no adverse reactions, and the quality of life returned to normal. Effective: Lesions and clinical symptoms were greatly improved according to X-ray examination, there were no adverse reactions, and the quality of life was obviously improved. Ineffective: lesions and clinical symptoms were not improved or exacerbated according to X-ray examination, there were adverse reactions, and the quality of life was poor. Total effective rate $=($ cured cases + effective cases $) /$ no. of cases x 100\%. Treatment costs were recorded.

Statistical analysis. Statistical analysis was performed using SPSS v.17.0 (SPSS, Inc., Chicago, IL, USA). Measurement data were presented as mean \pm standard deviation (mean $\pm \mathrm{SD}$ ). One-way analysis of variance followed by post hoc test (Least Significant Difference) was used for the comparison of means among groups, and repeated measures analysis of variance was used for the data comparison at different time-points within the group. The Chi-square test was used for enumeration data. $\mathrm{P}<0.05$ was considered to indicate a statistically significant difference.

\section{Results}

General clinical data of patients in the 4 groups. There were no statistically significant differences in sex, age, course of disease, red blood cell (RBC) count, platelet (PLT) count and hemoglobin $(\mathrm{Hb})$ among the 4 groups $(\mathrm{P}>0.05$; Table I).

WBC counts in the 4 groups of patients before and after treatment. No statistically significant differences were found in the WBC count in patients among the 4 groups at 1 day before treatment and at 1,4 and 7 days after treatment $(\mathrm{P}>0.05)$. Compared with those at 1 day before treatment, WBC counts in patients in the 4 groups were significantly decreased at 1,4 and 7 days after treatment $(\mathrm{P}<0.01)$. Compared with those at 1 day after treatment, WBC counts in patients in the 4 groups were significantly decreased at 4 and 7 days after treatment $(\mathrm{P}<0.01)$. Compared with those at 4 days after treatment, WBC counts in patients in the 4 groups were obviously decreased at 7 days after treatment $(\mathrm{P}<0.01$; Table II).

CRP in the 4 groups of patients before and after treatment. There were no statistically significant differences in the CRP measured value in patients among the 4 groups at 1 day before treatment and at 1, 4 and 7 days after treatment $(\mathrm{P}>0.05)$. Compared with those at 1 day before treatment, CRP measured values in patients in the 4 groups were obviously decreased at 1,4 and 7 days after treatment $(\mathrm{P}<0.01)$. Compared with those at 1 day after treatment, CRP measured values in patients in the 4 groups were obviously decreased at 4 and 7 days after treatment $(\mathrm{P}<0.01)$. Compared with those at 4 days after treatment, CRP measured values in patients in the 4 groups were significantly decreased at 7 days after treatment $(\mathrm{P}<0.01$; Table III).

Therapeutic effects in the 4 groups of patients. No adverse reactions occurred in the 4 groups of patients during treatment. In Group A, there were 21 cured cases $(42.00 \%)$, 26 effective cases $(52.00 \%)$ and 3 ineffective cases $(6.00 \%)$, with a total effective rate of $94.00 \%$. In Group B, there were 
Table I. General clinical data of patients in the 4 groups (mean \pm SD).

\begin{tabular}{|c|c|c|c|c|c|c|}
\hline Item & Group A $(n=50)$ & Group B $(n=50)$ & Group C $(\mathrm{n}=50)$ & Group D $(\mathrm{n}=50)$ & $\mathrm{F} / \chi^{2}$ & P-value \\
\hline $\operatorname{Sex}[\mathrm{n}(\%)]$ & & & & & 1.200 & 0.752 \\
\hline Male & $21(42.00)$ & $23(46.00)$ & $19(38.00)$ & $24(48.00)$ & & \\
\hline Female & $29(58.00)$ & $27(54.00)$ & $31(62.00)$ & $26(52.00)$ & & \\
\hline Age (years) & $35.44 \pm 2.16$ & $35.14 \pm 2.01$ & $34.52 \pm 2.35$ & $34.68 \pm 2.46$ & 1.755 & 0.157 \\
\hline Course of disease (days) & $8.46 \pm 6.62$ & $7.87 \pm 4.49$ & $7.73 \pm 5.96$ & $8.33 \pm 6.34$ & 0.177 & 0.911 \\
\hline $\mathrm{RBC}\left(\mathrm{x} 10^{12} / \mathrm{l}\right)$ & $4.64 \pm 0.43$ & $4.61 \pm 0.38$ & $4.51 \pm 0.31$ & $4.53 \pm 0.53$ & 1.102 & 0.349 \\
\hline $\operatorname{PLT}\left(\times 10^{9} / 1\right)$ & $183.72 \pm 29.45$ & $188.7 \pm 32.84$ & $191.53 \pm 28.77$ & $185.16 \pm 33.67$ & 0.635 & 0.592 \\
\hline $\mathrm{Hb}(\mathrm{g} / \mathrm{l})$ & $134.57 \pm 6.93$ & $133.75 \pm 7.65$ & $135.59 \pm 6.11$ & $132.46 \pm 6.01$ & 1.946 & 0.123 \\
\hline
\end{tabular}

Mean \pm SD, mean \pm standard deviation; RBC, red blood cell; PLT, platelet; Hb, hemoglobin.

Table II. Comparisons of WBC count among the 4 groups of patients before and after treatment $\left(\mathrm{x} 10^{9} / \mathrm{l}\right)(\mathrm{mean} \pm \mathrm{SD})$.

\begin{tabular}{|c|c|c|c|c|c|c|}
\hline Time & Group A $(n=50)$ & Group B $(n=50)$ & Group C $(n=50)$ & Group D $(n=50)$ & $\mathrm{F}$ & P-value \\
\hline 1 day before treatment & $15.35 \pm 4.39$ & $16.23 \pm 5.34$ & $15.63 \pm 4.34$ & $16.63 \pm 5.33$ & 0.703 & 0.551 \\
\hline 1 day after treatment & $12.96 \pm 3.69^{\mathrm{a}}$ & $12.28 \pm 3.94^{\mathrm{a}}$ & $12.85 \pm 4.01^{\mathrm{a}}$ & $11.98 \pm 4.25^{\mathrm{a}}$ & 0.686 & 0.561 \\
\hline 4 days after treatment & $9.13 \pm 2.54^{\mathrm{a}, \mathrm{b}}$ & $10.25 \pm 2.43^{\mathrm{a}, \mathrm{b}}$ & $9.25 \pm 2.25^{\mathrm{a}, \mathrm{b}}$ & $9.42 \pm 2.54^{\mathrm{a}, \mathrm{b}}$ & 2.144 & 0.096 \\
\hline 7 days after treatment & $7.51 \pm 2.13^{\mathrm{a}-\mathrm{c}}$ & $7.26 \pm 2.38^{\mathrm{a}-\mathrm{c}}$ & $7.36 \pm 2.16^{\mathrm{a}-\mathrm{c}}$ & $6.97 \pm 2.37^{\mathrm{a}-\mathrm{c}}$ & 0.506 & 0.678 \\
\hline $\mathrm{F}$ & 58.060 & 50.980 & 61.040 & 58.240 & - & - \\
\hline P-value & $\mathrm{P}<0.001$ & $\mathrm{P}<0.001$ & $\mathrm{P}<0.001$ & $\mathrm{P}<0.001$ & - & - \\
\hline
\end{tabular}

Mean $\pm \mathrm{SD}$, mean \pm standard deviation. ${ }^{\mathrm{a}} \mathrm{P}<0.01$ vs. 1 day before treatment. ${ }^{\mathrm{b}} \mathrm{P}<0.01$ vs. 1 day after treatment. ${ }^{\mathrm{c}} \mathrm{P}<0.01$ vs. 4 days after treatment.

Table III. Comparisons of CRP among the 4 groups of patients before and after treatment (mg/l) (mean \pm SD).

\begin{tabular}{|c|c|c|c|c|c|c|}
\hline Time & Group A (n=50) & Group B $(n=50)$ & Group C $(\mathrm{n}=50)$ & Group D $(n=50)$ & $\mathrm{F}$ & P-value \\
\hline 1 day before treatment & $49.36 \pm 19.35$ & $54.28 \pm 20.27$ & $52.17 \pm 22.63$ & $56.47 \pm 18.63$ & 1.062 & 0.366 \\
\hline 1 day after treatment & $44.36 \pm 14.53^{\mathrm{a}}$ & $39.85 \pm 13.74^{\mathrm{a}}$ & $42.58 \pm 14.29^{\mathrm{a}}$ & $41.83 \pm 14.09^{\mathrm{a}}$ & 0.868 & 0.458 \\
\hline 4 days after treatment & $21.26 \pm 11.29^{\mathrm{a}, \mathrm{b}}$ & $19.67 \pm 10.37^{\mathrm{a}, \mathrm{b}}$ & $20.87 \pm 9.38^{\mathrm{a}, \mathrm{b}}$ & $22.42 \pm 8.13^{\mathrm{a}, \mathrm{b}}$ & 0.661 & 0.577 \\
\hline 7 days after treatment & $2.19 \pm 0.87^{\mathrm{a}-\mathrm{c}}$ & $2.23 \pm 0.93^{\mathrm{a}-\mathrm{c}}$ & $2.11 \pm 1.01^{\mathrm{a}-\mathrm{c}}$ & $2.35 \pm 0.96^{\mathrm{a}-\mathrm{c}}$ & 0.561 & 0.641 \\
\hline $\mathrm{F}$ & 133.500 & 146.900 & 125.000 & 180.700 & - & - \\
\hline P-value & $\mathrm{P}<0.001$ & $\mathrm{P}<0.001$ & $\mathrm{P}<0.001$ & $\mathrm{P}<0.001$ & - & - \\
\hline
\end{tabular}

$\mathrm{CRP}$, C-reactive protein mean $\pm \mathrm{SD}$, mean \pm standard deviation. ${ }^{\mathrm{a}} \mathrm{P}<0.01$ vs. 1 day before treatment. ${ }^{\text {b }}<<0.01$ vs. 1 day after treatment. ${ }^{\mathrm{c}} \mathrm{P}<0.01$ vs. 4 days after treatment.

Table IV. Comparisons of therapeutic effects among the 4 groups of patients [n (\%)].

\begin{tabular}{|c|c|c|c|c|c|}
\hline Group & $\mathrm{n}$ & Cured & Effective & Ineffective & $\begin{array}{c}\text { Total } \\
\text { effective rate }\end{array}$ \\
\hline Group A & 50 & $21(42.00)$ & $26(52.00)$ & $3(6.00)$ & 47 (94.00) \\
\hline Group B & 50 & $19(38.00)$ & $27(54.00)$ & $4(8.00)$ & $46(92.00)$ \\
\hline Group C & 50 & $24(48.00)$ & $24(48.00)$ & $2(4.00)$ & $48(96.00)$ \\
\hline Group D & 50 & $20(40.00)$ & $25(50.00)$ & $5(10.00)$ & $45(90.00)$ \\
\hline$\chi^{2}$ & - & - & - & - & 1.536 \\
\hline P-value & - & - & - & - & 0.664 \\
\hline
\end{tabular}




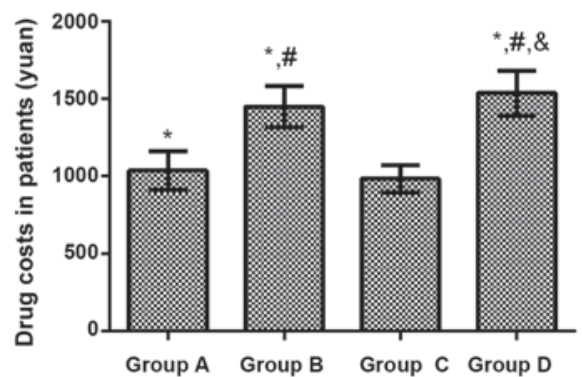

Figure 1. Drug costs in the 4 groups of patients. Compared with that in group $\mathrm{C}$, treatment costs of patients were significantly increased in group A, group $\mathrm{B}$ and $\mathrm{D}(\mathrm{P}<0.01)$. Compared with that in group $\mathrm{A}$, treatment costs of patients were significantly increased in group $\mathrm{B}$ and $\mathrm{D}(\mathrm{P}<0.01)$. Compared with that in group $\mathrm{D}$, the treatment cost of patients in group $\mathrm{D}$ was increased obviously $(\mathrm{P}<0.01)$. Compared with group $\mathrm{C},{ }^{*} \mathrm{P}<0.01$; compared with group $\mathrm{A},{ }^{\#} \mathrm{P}<0.01$; compared with group $\mathrm{B},{ }^{\&} \mathrm{P}<0.01$.

19 cured cases (38.00\%), 27 effective cases (54.00\%) and 4 ineffective cases $(8.00 \%)$, with a total effective rate of $92.00 \%$. In Group C, there were 24 cured cases $(48.00 \%)$, 24 effective cases $(48.00 \%)$ and 2 ineffective case $(4.00 \%)$, with a total effective rate of $96.00 \%$. In Group D, there were 20 cured cases $(40.00 \%), 25$ effective cases $(50.00 \%)$ and 5 ineffective cases $(10.00 \%)$, with a total effective rate of $90.00 \%$. The total effective rate indicated no statistically significant difference among the 4 groups of patients (P>0.05; Table IV).

Drug costs in the 4 groups of patients. The treatment cost was (1037.15 \pm 126.51$)$ yuan in Group A treated with ceftriaxone sodium, (1451.38 \pm 134.55$)$ yuan in Group B treated with ceftizoxime sodium, (983.67 \pm 86.37$)$ yuan in Group $\mathrm{C}$ treated with levofloxacin and $(1537.45 \pm 146.59)$ yuan in Group D treated with azithromycin. Compared with that in Group C, treatment costs of patients were significantly increased in Group A, Group B and Group D $(\mathrm{P}<0.01)$. Compared with that in Group A, treatment costs of patients were remarkably increased in Group B and Group D $(\mathrm{P}<0.01)$. Compared with that in Group B, the treatment cost of patients in Group D was increased obviously $(\mathrm{P}<0.01$; Fig. 1$)$.

\section{Discussion}

LRTI is the most common infectious disease in clinic, which is often caused by bacterial, viral and chlamydia infections (7). LRTI often seriously threatens the physical health of patients, leading to low immune function and abnormal changes in the body's inflammatory indexes. Both WBC and CRP are indexes closely related to LRTI, and the effective detection indexes for the diagnosis of patients with respiratory tract infection $(8,9)$. Antibiotics are dominated in the clinical treatment of LRTI, and there are a variety of different therapeutic regimens. Injection therapy of large-dose antibiotics lead to enhanced drug resistance of pathogens $(10,11)$. During treatment, the increase in the drug costs often lays a heavy economic burden on patients. Therefore, selecting the appropriate drug therapeutic regimen and reducing the drug costs can greatly reduce the economic burden while improving the physical health of patients, which is of vital significance in clinic.
Ceftriaxone sodium, ceftizoxime sodium, levofloxacin and azithromycin are often applied in the clinical treatment of LRTI (12). As the third-generation cephalosporin antibiotic drugs, ceftriaxone sodium and ceftizoxime sodium are characterized by strong therapeutic effects and broad antibacterial spectrum. Ceftriaxone sodium has always been a kind of safe and reliable antibacterial drug in the treatment of LRTI, but it has high drug resistance (13). Ceftizoxime sodium is too expensive to be accepted by most patients. As a quinolone antibacterial drug, levofloxacin is characterized by a potent antibacterial effect and broad antibacterial spectrum, which can inhibit the activity of DNA gyrase in bacteria with a good antibacterial efficacy (14). Azithromycin, as a macrolide antibiotic, can inhibit a variety of bacteria with a broad antibacterial spectrum, which can reduce the incidence rate of adverse reactions in patients, and has been widely applied in clinic (15). In the present study, the total effective rate was $94.00 \%$ in Group A in the treatment of LRTI with ceftriaxone sodium, $92.00 \%$ in Group B, 96.00\% in Group C and $90.00 \%$ in Group D. There were no differences in the total effective rate of treatment among the 4 groups of patients, and there were no adverse reactions during treatment. The above results indicate that the 4 kinds of antibacterial drugs have good antibacterial efficacy, and their curative effects are well consistent in the treatment of LRTI. Di Marco et al (16), studied and showed that curative effects of ceftriaxone sodium, ceftizoxime sodium, levofloxacin and azithromycin are satisfactory in the treatment of LRTI, which are similar to results in the present study. However, studies have revealed that azithromycin has a better therapeutic effect $(12,15)$. Such a difference is possibly due to different objects and courses of disease in the present study, so the conclusion needs further verification.

The WBC count in the body is changed due to a variety of inflammatory responses and bacterial infections. WBC includes monocytes, lymphocytes and granulocytes, and changes in its count reflect the body's immune function and bacterial infection (17). CRP is a kind of globulin synthesized by the liver, as well as a reactive protein produced when there are concurrent inflammations or injuries in the body. When inflammation or infection occurs in the body, the synthesis of CRP will be rapidly increased and can reach the peak within $50 \mathrm{~h}$. CRP is sensitive to, not only bacterial infection, but also chronic inflammatory response, acute trauma, burns and viral infection, whose level often has a positive correlation with the severity of disease $(18,19)$. Results in the present study demonstrated that both WBC count and CRP measured values significantly declined in the 4 groups of patients at 1, 4 and 7 days after treatment compared with those at 1 day before treatment. Compared with those at 1 day after treatment, both WBC count and CRP measured values were significantly decreased in the 4 groups of patients at 4 and 7 days after treatment. Besides, both WBC count and CRP measured values were obviously decreased in the 4 groups of patients at 7 days after treatment compared with those at $4 \mathrm{~d}$ after treatment. The above findings indicate that WBC and CRP can be used to dynamically monitor the treatment of LRTI and accurately observe the disease evolution and treatment effect on patients. WBC and CRP can serve as monitoring indexes for LRTI, which is similar to the research conclusion of Ben Amar et al (20). 
The growth of medical costs has always attracted social concern, which has an extremely important influence on the daily life of patients. According to results in the present study, compared with that in Group $\mathrm{C}$, treatment costs of patients were significantly increased in Group A, Group B and Group D. Compared with that in Group A, treatment costs of patients were remarkably increased in Group B and Group D. Compared with that in Group B, the treatment cost of patients in Group D was increased obviously. The curative effects of the 4 kinds of antibiotics were well consistent in the treatment of LRTI. Under the premise of ensuring the therapeutic effect, the treatment cost of levofloxacin is the lowest in economic terms.

Subjects in the present study were screened in strict accordance with the inclusion and exclusion criteria. There were no differences in general clinical data, such as sex, age, course of disease, RBC count, PLT count and Hb, among patients enrolled, thus ensuring the reliability of the study. However, etiological monitoring and drug susceptibility test were not performed for the 4 groups of patients in this study, and the drug resistance mechanisms of the 4 kinds of antibiotics were not investigated, so there were certain limitations. Therefore, it is expected that bacterial culture and drug susceptibility test can be performed for patients with LRTI in subsequent investigations to verify the results in the present study.

In conclusion, ceftriaxone sodium, ceftizoxime sodium, levofloxacin, and azithromycin have excellent antibacterial efficacy. WBC and CRP can be used to dynamically monitor the treatment of LRTI and accurately observe the disease evolution and treatment effect on patients. The treatment cost of levofloxacin is the lowest in economic terms; thus, it is worthy of clinical promotion and application.

\section{Acknowledgements}

Not applicable.

\section{Funding}

No funding was received.

\section{Availability of data and materials}

The datasets used and/or analyzed during the present study are available from the corresponding author on reasonable request.

\section{Authors' contributions}

LZ drafted the present study. LZ and BL collected the patient data. $\mathrm{LZ}, \mathrm{BL}$ and $\mathrm{CW}$ analyzed the patient data. All the authors read and approved the final manuscript.

\section{Ethics approval and consent to participate}

The present study was approved by the Ethics Committee of Dongying People's Hospital (Dongying, China). Signed written informed consents were obtained from the patients and/or guardians.

\section{Patient consent for publication}

Not applicable.

\section{Competing interests}

The authors declare that they have no competing interests.

\section{References}

1. Houston MS, Silverstein MD and Suman VJ:Community-acquired lower respiratory tract infection in the elderly: A community-based study of incidence and outcome. J Am Board Fam Pract 8: 347-356, 1995.

2. Jiang W, Yin F, Zhou W, Yan Y and Ji W: Clinical significance of different virus load of human bocavirus in patients with lower respiratory tract infection. Sci Rep 6: 20246, 2016.

3. Chiricozzi E, Loberto N, Schiumarini D, Samarani M, Mancini G, Tamanini A, Lippi G, Dechecchi MC, Bassi R, Giussani P, et al: Sphingolipids role in the regulation of inflammatory response: From leukocyte biology to bacterial infection. J Leukoc Biol 103: 445-456, 2018.

4. Honda T, Uehara T, Matsumoto G, Arai S and Sugano M: Neutrophil left shift and white blood cell count as markers of bacterial infection. Clin Chim Acta 457: 46-53, 2016.

5. Muloiwa R, Dube FS, Nicol MP, Zar HJ and Hussey GD: Incidence and diagnosis of pertussis in South African children hospitalized with lower respiratory tract infection. Pediatr Infect Dis J 35: 611-616, 2016.

6. Hu S, Jiang T, Zhang X, Zhou Y, Yi Z, Wang Y, Zhao S, Wang M, Ming D and Chen S: Elizabethkingia anophelis isolated from patients with multiple organ dysfunction syndrome and lower respiratory tract infection: Report of two cases and literature review. Front Microbiol 8: 382, 2017.

7. Mazur NI, Martinón-Torres F, Baraldi E, Fauroux B, Greenough A, Heikkinen T, Manzoni P, Mejias A, Nair H, Papadopoulos NG, et al: Respiratory Syncytial Virus Network (ReSViNET): Lower respiratory tract infection caused by respiratory syncytial virus: Current management and new therapeutics. Lancet Respir Med 3: 888-900, 2015.

8. Cohen C, Moyes J, Tempia S, Groome M, Walaza S, Pretorius M, Naby F, Mekgoe O, Kahn K, von Gottberg A, et al: Epidemiology of acute lower respiratory tract infection in HIV-exposed uninfected infants. Pediatrics 137: 137, 2016.

9. Yoshihara K, Le MN, Okamoto M, Wadagni AC, Nguyen HA, Toizumi M, Pham E, Suzuki M, Nguyen AT, Oshitani H, et al: Association of RSV-A ON1 genotype with increased pediatric acute lower respiratory tract infection in Vietnam. Sci Rep 6: 27856, 2016

10. Lodise TP Jr, Miller C, Patel N, Graves J and McNutt LA: Identification of patients with Pseudomonas aeruginosa respiratory tract infections at greatest risk of infection with carbapenem-resistant isolates. Infect Control Hosp Epidemiol 28: 959-965, 2007.

11. Volturo GA, Low DE and Aghababian R: Managing acute lower respiratory tract infections in an era of antibacterial resistance. Am J Emerg Med 24: 329-342, 2006.

12. Kraus EM, Pelzl S, Szecsenyi J and Laux G: Antibiotic prescribing for acute lower respiratory tract infections (LRTI)-guideline adherence in the German primary care setting: An analysis of routine data. PLoS One 12: e0174584, 2017.

13. Shah AJ, Mulla SA and Revdiwala SB: Neonatal sepsis: High antibiotic resistance of the bacterial pathogens in a neonatal intensive care unit of a tertiary care hospital. J Clin Neonatol 1: 72-75, 2012.

14. Abdul-Aziz MH, Lipman J, Mouton JW, Hope WW and Roberts JA: Applying pharmacokinetic/pharmacodynamic principles in critically ill patients: Optimizing efficacy and reducing resistance development. Semin Respir Crit Care Med 36: 136-153, 2015.

15. Serisier DJ: Inhaled antibiotics for lower respiratory tract infections: Focus on ciprofloxacin. Drugs Today (Barc) 48: 339-351, 2012. 
16. Di Marco F, Braido F, Santus P, Scichilone N and Blasi F: The role of cefditoren in the treatment of lower community-acquired respiratory tract infections (LRTIs): From bacterial eradication to reduced lung inflammation and epithelial damage. Eur Rev Med Pharmacol Sci 18: 321-332, 2014.

17. Thompson AA, Dickinson RS, Murphy F, Thomson JP, Marriott HM, Tavares A, Willson J, Williams L, Lewis A, Mirchandani A, et al: Hypoxia determines survival outcomes of bacterial infection through HIF-1alpha dependent re-programming of leukocyte metabolism. Sci Immunol 2: eaa12861, 2017.

18. Kim JH, Lee JY, Cho HR, Lee JS, Ryu JM and Lee J: High concentration of C-reactive protein is associated with serious bacterial infection in previously healthy children aged 3 to 36 months with fever and extreme leukocytosis. Pediatr Emerg Care 1, 2017
19. Durán A, González A, Delgado L, Mosquera J and Valero N: Serum level of C-reactive protein is not a parameter to determine the difference between viral and atypical bacterial infections. J Med Virol 88: 351-355, 2016

20. Ben Amar J, Zaibi H, Bouzid K, Azzabi S, Bacca MA, Dahari B and Aouina $\mathrm{H}$ : Role of procalcitonin and c-reactive protein levels: A diagnostic tool in lower respiratory tract infections. Tunis Med 94: 176-180, 2016.

c) (7) (2) This work is licensed under a Creative Commons cc) International (CC BY-NC-ND 4.0) License. 